\title{
Immunological crossreactivity of the antisera to purified hormones
}

\author{
G. S. MURTHY* and N. R. MOUDGAL \\ Centre for Advanced Research in Reproductive Biology (ICMR), Laboratory of Endocrine \\ Biochemistry, Department of Biochemistry, Indian Institute of Science, Bangalore 560012 , \\ India
}

MS received 28 July 1986; revised 3 January 1987

\begin{abstract}
Antisera to ovine follicle stimulating hormone free of ovine lutinising hormone contamination has been obtained in monkeys. These antisera have been shown to be able to crossreact with ovine lutinising hormone. Quantitation of the binding data for ovine follicle stimulating hormone and ovine lutinising hormone show that $10-40 \%$ of the total antibody population to ovine follicle stimulating hormone can bind to ovine lutinising hormone and the affinity constant for ovine lutinising hormone is about 2-20 times lesser than for ovine follicle stimulating hormone. These binding data indicate that there are common epitopes exposed in ovine follicle stimulating hormone and ovine lutinising hormone through the $\alpha$ subunit. Results are obtained which match with the above conclusions when ovine lutinising hormone antisera is analysed for ovine follicle stimulating hormone binding. These results show that the $\alpha$-subunit when combined with different $\beta$-subunits will have common epitopes exposed, but would be sterically disposed differently in the two hormones.
\end{abstract}

Keywords. Gonadotropins; epitopes.

\section{Introduction}

Termination of pregnancy in experimental animals through passive/active immunisation is a well documented scientific phenomenon (Stevens, 1973; Mukku et al., 1974; Raj et al., 1974; Sundaram et al., 1976; Adiga and Ramana Murthy, 1983; Sheela Rani and Moudgal, 1983; Chandana Das et al., 1985; Wickings et al., 1982). This method of approach to human contraception is under way in many laboratories (Talwar et al., 1976; Nash et al., 1980; Moudgal et al., 1985) it is desirable to learn more about the antisera generated for hormones in terms of specificity and crossreactivity. The hormones which have a definite role in reproduction in primates and incidentally have structural similarity are follicle stimulating hormone (FSH), lu tinising hormone (LH) and human chorionic gonadotropin (hCG). Thus it is of practical value to investigate carefully into the specificities of the antisera obtained in animals for these purified hormones.

Antiserum raised to a pure hormone is considered very specific as has been frequently determined by its biological characterisation. Gonadotropins, specially FSH, LH and hCG, have a common $\alpha$-subunit (molecular weight 17000) and variable $\beta$-subunits (molecular weight 18000-20000). On the basis of this structure one can assume that all the 3 hormones could have a large number of common epitopes (nearly $50 \%$ of the total structure is homologous), and this on the basis of

\footnotetext{
*To whom all correspondence should be addressed.

Abbreviations used: FSH, Follicle stimulating hormone; LH, lutinising hormone; hCG, human chorionic gonadotropin; oFSH, ovine FSH; oLH, ovine LH; BSA, bovine serum albumin; RIA, radioimmunoassay; EPS, epoxy-Sepharose; hLH, human LH.
} 
molecular weight should be significant. Thus the antisera raised to ovine FSH (oFSH) can be expected to be crossreacting immunologically with ovine LH (oLH) significantly. However the data presented in the literature (Rao and Moudgal, 1970; Moudgal et al., 1985) indicate very minimal cross reactivity in the antisera raised to hormones. The reason ascribed for lack of crossreactivity are many, (i) The $\alpha$-subunit is supposed to be very poorly antigenic and hence low titres of antisera directed to the epitopes on the $\alpha$-subunit that could be present in the whole molecule. (ii) During the $\alpha$-, $\beta$-complex formation most of the $\alpha$-subunit is buried in the $\beta$ subunit, leaving very little of the $\alpha$-structure to be exposed to the solvent for eliciting antibody response in the animal. (iii) The $\alpha$-subunit is totally non immunogenic and the cross reactivity is due to the contaminant hormone present in the antigen used for immunisation, and as such each antiserum is having noncrossreacting antibodies to both hormones. The last suggestion has gained value as the antigens used in most cases are infact highly or marginally contaminated with the other antigen. In the present paper we report on the nature of the immunological crossreactivity/specificity of the antisera obtained for hormone $(\mathrm{oLH} / \mathrm{oFSH})$ preparations which are highly purified and freed of contaminating hormones by affinity chromotography.

\section{Materials and methods}

Bovine serum albumin (BSA) and butanediol diglycidyl ether were products from Sigma Chemical Company, St. Louis, Missouri, USA. Sepharose was a product of Pharmacia, Sweden. oFSH and oLH were prepared from locally procured sheep pituitaries by procedures standardised in the laboratory. The procedure essentially followed the method of Sairam (1979), with slight modifications. oLH was $90-100 \%$ pure and had $<0.01 \%$ contamination of oFSH, while oFSH was $90-100 \%$ pure and had a oLH contamination of about $4 \%$ as measured by radioimmunoassay (RIA). Disc electrophoresis of these preparations gave a single diffuse band as expected for glycoprotein hormones with no additional band.

All the binding studies were done in $0.05 \mathrm{M}$ phosphate buffer containing $0 \cdot 1 \% \mathrm{BSA}$ $\mathrm{pH} 7 \cdot 2$.

\section{Antisera production}

All antisera were raised by the conventional method using Freund's complete adjuvant by the standard procedure. Briefly young rabbits were immunised with $200 \mu \mathrm{g}$ of $\mathrm{oLH}$ in Freund's complete adjuvant intradermally at weekly intervals for 4 weeks. Subsequently booster shots of $100 \mu \mathrm{g}$ oLH in saline was administered subcutaneously and antisera were collected after 14 days after the booster shot. Antisera to oFSH were all raised in monkeys using oFSH adsorbed on commercial aluminium hydroxide. Male monkeys (Macaca radiata) of 5-6 years age were immunised with oFSH adsorbed on alugel ( $1 \mathrm{mg} \mathrm{oFSH} / \mathrm{ml}$ alugel) with primary immunisation dose of $1 \mathrm{mg}, 300 \mu \mathrm{g}, 100 \mu \mathrm{g}$ and $100 \mu \mathrm{g}$ at intervals of 8 days, given intradermally. Booster shots were subsequently administered at 50 day intervals using $100 \mu \mathrm{g}$ of oFSH adsorbed on alugel. Antisera used in the studies were collected from animals which were on this immunisation schedule for 150-200 days, the antisera being collected 14 days after the booster dose. These antisera were used for further studies without any further treatment. 
Immobilisation of oLH and oLH antibody on epoxy-Sepharose

Freshly prepared epoxy-Sepharose (EPS) $(2 \mathrm{ml})$ was equilibrated with $1 \mathrm{M}$ sodium carbonate and coupled to $10 \mathrm{mg}$ of oLH in the same solution in a total volume of $4 \mathrm{ml}$ (Murthy and Moudgal, 1986). Coupling was allowed to occur overnight at room temperature. The gel was thoroughly washed and stored at $4^{\circ} \mathrm{C}$ until use. The immobilised oLH (oLH-EPS) had $5 \mathrm{mg} \mathrm{oLH} / \mathrm{ml}$ of gel.

oLH antibody $(5 \mathrm{ml})$ was coupled to freshly prepared EPS $(10 \mathrm{ml})$ by the same procedure as outlined above, using the immunoglobulin-G fraction of the antiserum. The gel obtained had a capacity to bind about $500 \mu \mathrm{g}$ of $\mathrm{oLH} / \mathrm{ml}$ of the gel.

\section{Affinity purification of antigen (oFSH)}

oFSH (10 mg containing $4 \% \mathrm{oLH})$ in $4 \mathrm{ml}$ of $0.9 \%$ sodium chloride was passed through a column of oLH antibody-EPS $(2 \mathrm{ml})$ and recirculated 4-5 times before washing the column with water. The extent of oLH removal was quantitated by using a standard RIA system and contamination of oLH as measured by RIA was $<0 \cdot 1 \%$. This material was used for raising antisera in the monkeys. oLH purified from sheep pituitaries had $<0.01 \%$ contamination and as such used for immunisation as well as coupling to EPS.

\section{Iodination of hormones}

Iodination of hormones was carried out by chloramine $\mathrm{T}$ procedure (Rao et al., 1984). The specific activity of the iodinated hormones was in the range of 50$100 \mu \mathrm{Ci} / \mathrm{mg}$ protein.

\section{Binding of $\left[{ }^{125} I\right]$-hormones to antisera}

This was carried out in $0.05 \mathrm{M}$ phosphate buffer, $\mathrm{pH} 7 \cdot 2$, at room temperature for $20 \mathrm{~h}$ in a final volume of $0.5 \mathrm{ml}$. The separation of the bound label from free label was effected by polyethylene glycol double antibody method (double antibody precipitation done in the presence of $1 \cdot 25-2.5 \%$ polyethylene glycol for $20 \mathrm{~min}$ ). The bound radioactivity was counted in a LKB Clinigamma counter.

\section{Adsorption of antibodies on oLH-EPS}

This approach was used to prove experimentally that the crossreacting species of antibody present in the antisera is infact the antibody that is elicited in response to the antigen and not in response to the contaminated 'antigen analogue'. We assume that the antigen $(\mathrm{oLH})$ is pure and all the antibodies that are obtained bind to oLH and a part of this antibody population binds to oFSH (those species of antibodies that are directed to the common epitope). If this is the hypothesis, adsorption of antibodies by oLH-EPS should result in parallel decrease in the oLH and oFSH binding. Thus, if contamination of the antigen is the reason, for crossreaction, the above treatment results in the selective depletion of the oLH binding without 
affecting oFSH binding. Otherwise, the depletion of the oLH and oFSH binding should be parallel after the oLH-EPS treatment.

Antiserum $(50 \mu \mathrm{l})$ was taken in $200 \mu \mathrm{l}$ of RIA buffer and mixed with 5-50 $\mu \mathrm{g}$ of the oLH-EPS suspension in a total volume of $0.5 \mathrm{ml}$. Control tubes had the same volume of the antiserum and 5-50 $\mathrm{mg}$ of sepharose in a total volume of $0.5 \mathrm{ml}$. The tubes were shaken intermittantly at room temperature for $2 \mathrm{~h}$. The suspension was diluted to $1 \mathrm{ml}$ and spun. The supernatant was used for checking the binding of $\left[{ }^{125} \mathrm{I}\right]-\mathrm{oLH}$ and $\left[{ }^{125} \mathrm{I}\right]-\mathrm{oFSH}$ by the procedure described above. All the binding data were normalised to undiluted serum.

\section{Scatchard plot analysis}

Affinity constants and capacity measurements of antisera were carried out by analysing the standard displacement profile for the hormone by Scatchard plot. Displacement analysis was carried out by standard procedure. In analysing the data, correction for the damage of the $\left[{ }^{125} \mathrm{I}\right]$-hormone during iodination/storage was applied as already described (Murthy and Friesen, 1985a,b).

Hormones used as antigens are henceforth referred to as antigens and the complementary hormone (hormone sharing the same $\alpha$-subunit) is referred to as antigen analogue. Thus, for oLH (antigen) oFSH is the antigen analogue and vice versa.

\section{Results}

Figure 1 shows the binding of oFSH antisera to $\left[{ }^{125} \mathrm{I}\right]-\mathrm{oFSH}$ and $\left[{ }^{125} \mathrm{I}\right]-\mathrm{oLH}$. It is seen that the binding of the antigen is very much more than the antigen analogue. The extent of cross reaction was calculated from such a plot and the data for 5

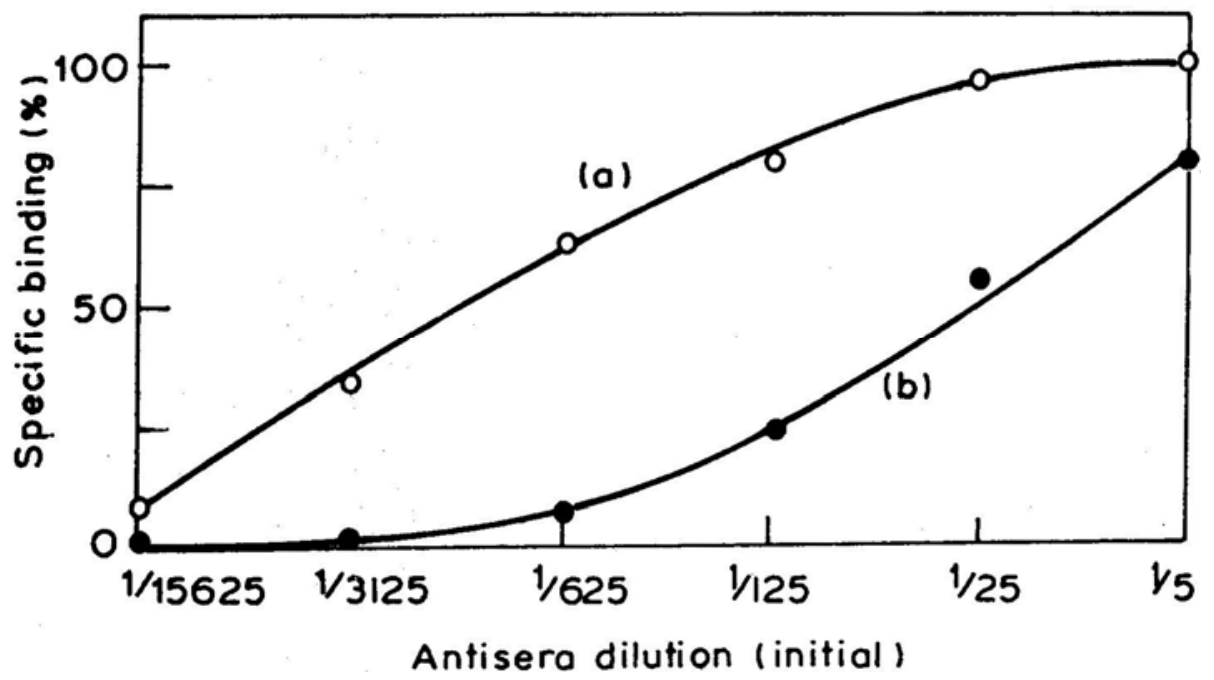

Figure 1. Binding of $\left[{ }^{125} \mathrm{I}\right]-\mathrm{oFSH}$ (a) and $\left[{ }^{125} \mathrm{I}\right]-\mathrm{oLH}$ (b) to oFSH antisera (M 428) at varying dilutions of the antisera. 
antisera are shown in table 1 . The cross reactivity is obviously small (2-4\%), but definite, clearly demonstrating that the antibody raised to a antigen (in this case oLH or oFSH) can give rise to a population of antibodies, albeit small, which can bind to antigen analogue.

Table 1. Specificity of binding of antisera raised to pure hormones.

\begin{tabular}{|c|c|c|c|c|}
\hline \multirow{2}{*}{$\begin{array}{c}\text { Antisera } \\
\text { code }\end{array}$} & \multirow{2}{*}{$\begin{array}{l}\text { Antigen } \\
\text { used }\end{array}$} & \multicolumn{2}{|c|}{$\begin{array}{l}\text { Dilution required for } \\
50 \% \text { binding }\end{array}$} & \multirow{2}{*}{$\begin{array}{l}\text { Crossreaction with } \\
\text { antigen analogue } \\
(\%)\end{array}$} \\
\hline & & IoFSH & IoLH & \\
\hline M 422 & oFSH & $1 / 3200$ & $1 / 125$ & $4 \cdot 0$ \\
\hline M 428 & oFSH & $1 / 1600$ & $1 / 55$ & $3 \cdot 5$ \\
\hline M 483 & oFSH & $1 / 1400$ & $1 / 25$. & 1.8 \\
\hline M 471 & oLH & $1 / 1100$ & $1 / 50000$ & $2 \cdot 2$ \\
\hline R 68 & $\mathrm{oLH}$ & $1 / 400$ & $1 / 25000$ & 1.6 \\
\hline
\end{tabular}

Figure 2 shows the binding characteristics of the oLH antiserum and oLH antiserum adsorbed on oLH-EPS ( 5 and $50 \mathrm{mg}$ ). A decrease in the binding ability for $\mathrm{oLH}$ as well as oFSH is seen. Relative loss of the binding ability to the hormones after adsorption with oLH-EPS is shown in table 2, for the two antisera. In all the 4 cases the relative losses are same for both oLH and oFSH. These data clearly support the hypothesis that the cross reactivity that is observed in the antisera is due to the presence of the antibody population directed against common epitope/s between the two hormones.

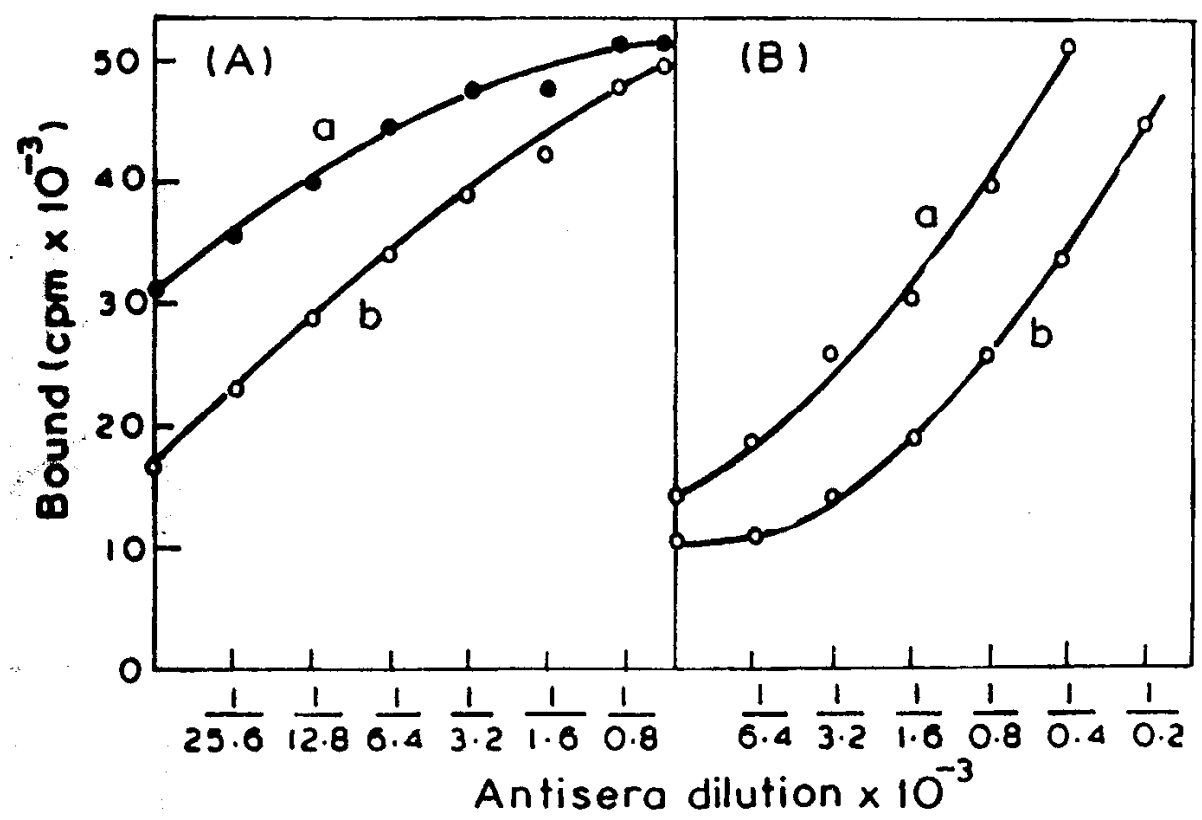

Figure 2. Binding of $\left[{ }^{125} \mathrm{I}\right]-\mathrm{oLH}$ (A) and $\left[{ }^{125} \mathrm{I}\right]-\mathrm{oFSH}$ (B) to oLH antiserum (R 68). Curve ' $a$ ' represents the binding of control antiserum and curve ' $b$ ' binding of the antiserum treated with $25 \mu \mathrm{l}$ of oLH-EPS. The antiserum concentrations on the $\mathrm{X}$-axis are normalised to undiluted serum. 
Table 2. Adsorption efficiency of the oLH antibodies by oLH-EPS.

\begin{tabular}{lcrr}
\hline \multirow{2}{*}{$\begin{array}{c}\text { Antisera } \\
\text { code }\end{array}$} & $\begin{array}{c}\text { volume of } \\
\text { oLH-EPS used }\end{array}$ & Loss of binding (\%) \\
\cline { 3 - 4 } & $(\mu \mathrm{l})$ & IoFSH & IoLHI \\
\hline M 471 & 200 & 100 & 100 \\
M 471 & 25 & 71 & 80 \\
M 471 & 0 & 0 & 0 \\
R 68 & 50 & 95 & 94 \\
R 68 & 5 & 52 & 52 \\
R 68 & 0 & 0 & 0 \\
\hline
\end{tabular}

Figure 3 presents the displacement profile of oLH antisera for oLH and oFSH. The inset presents corresponding Scatchard plot. Figure 4 shows the displacement profile for oLH antisera for both oLH and hCG, with corresponding Scatchard plots in the inset. It is seen that while the Scatchard plot is clearly linear for oLH it is nonlinear for hCG, showing two sets of affinity constants. This type of analysis has been done for a number of antisera and the results are presented in table 3. The data indicate the capacity as well as the apparent $K_{a}$ for different hormone systems. As a general rule, the $K_{a}$ for the antigen (hormone) is always very high compared to the antigen analogue. Likewise the capacity is also the highest for the antigen. The decrease in the $K_{a}$ for the antigen analogues ranges from 2-20 fold, decrease in capacities being $10-40 \%$. It should be noted here that the crossreactivity of these antisera were $<4 \%$ with the antigen analogue. Another point to be

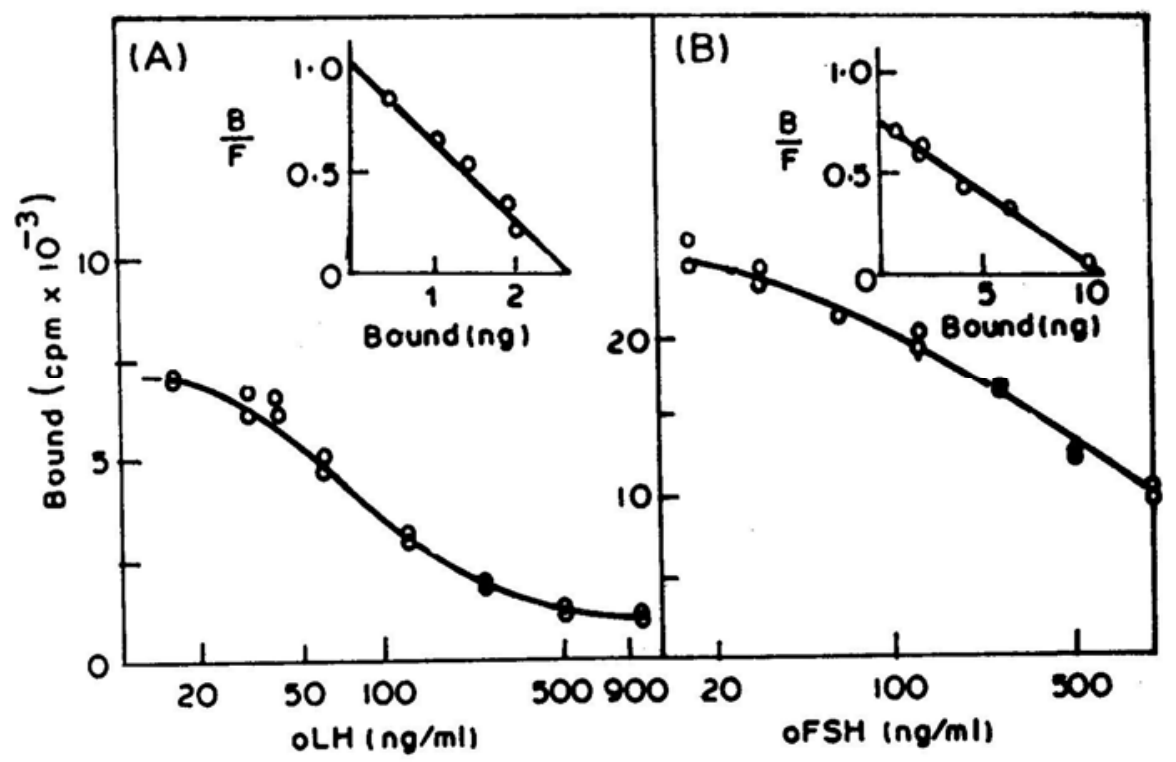

Figure 3. Competitive binding assay of oLH antiserum (R 68) for oLH. A. $\left[{ }^{125} \mathrm{I}\right]-\mathrm{oLH}$, $\mathrm{oLH}$ for displacement at antiserum dilution of $1 / 25000$ and for $\mathrm{oFSH}$. B. $\left[{ }^{125} \mathrm{I}\right]-\mathrm{oFSH}$, oFSH for displacement at antiserum dilution of $1 / 500$. The inset in each show corresponding Scatchard plots. 


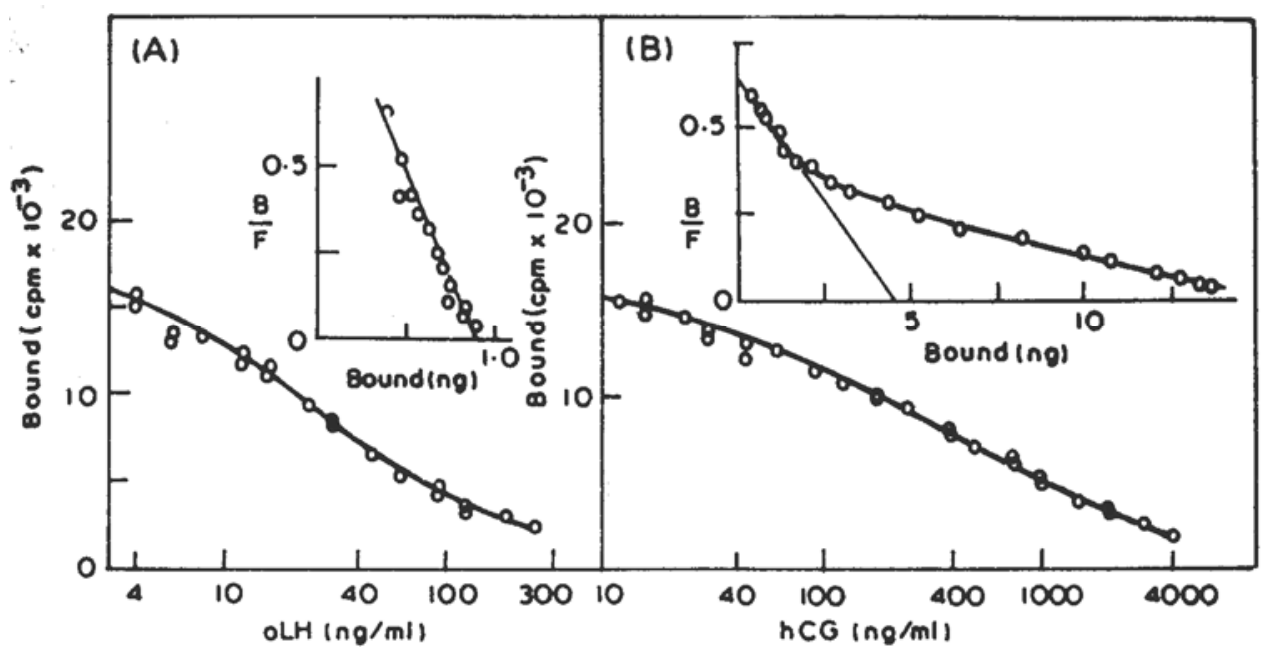

Figure 4. Competitive binding assay of oLH antiserum $(\mathrm{M} 471)$ to oLH. A. $\left[{ }^{125} \mathrm{I}\right]-\mathrm{oLH}$, $\mathrm{oLH}$ for displacement at antiserum dilution of $1 / 25000$ and to hCG. B. $\left[{ }^{125} \mathrm{I}\right]-\mathrm{hCG}$, hCG for displacement at antiserum dilution of $1 / 500$. The inset shows the corresponding Scatchard plots.

Table 3. Scatchard plot analysis of displacement profile of different antisera*.

\begin{tabular}{lccccccccc}
\hline & & \multicolumn{7}{c}{ Hormone ised for displacement } \\
Antisera & & oFSH & \multicolumn{2}{c}{ oLH } & hCG & hFSH \\
\cline { 3 - 9 } code & Antigen & Cap & $K_{a}$ & Cap & $K_{a}$ & Cap & $K_{a}$ & Cap & $K_{a}$ \\
\hline M 422 & oFSH & 15.3 & 1.15 & 1.57 & 1.05 & & & & \\
& & & & 1.50 & 0.35 & & & & \\
M 428 & oFSH & 11.0 & 5.80 & 3.25 & 1.20 & & & & \\
M 471 & oLH & 190.0 & 0.08 & 650 & 0.84 & &. & & \\
M 471-3 & oLH & & & 115 & 2.30 & 20.0 & 3.6 & & \\
& & & & & & 55.0 & 0.7 & & \\
R 68 & oLH & 65 & 0.11 & 725 & 0.73 & 84.0 & 0.6 & & \\
R 4-1 & hCG & & & 240 & 1.20 & 504 & 5.9 & 169 & 0.47 \\
\hline
\end{tabular}

*Capacity is measured as $\mu \mathrm{g} / \mathrm{ml}$ and $K_{a}$ presents affinity constant $\times 10^{-10}$.

observed is that in all cases of antigen-antibody interaction, the Scatchard plots show a single affinity, whereas in some antigen analogue-antibody systems two affinity constants are observed.

\section{Discussion}

On the basis that an immunological approach has a likely application in human fertility regulation it becomes very important to learn more about the nature of the crossreaction one can see in the antisera raised to pure hormones. One of the observations that always presented problems to the investigators in the field of reproduc- 
tive physiology has been the immunological crossreactivity for many antisera raised to gonadotropins. This has been mostly ascribed as due to antigenic impurity. The data presented here clearly demonstrates that antiserum to a very pure antigen crossreacts with antigen analogue, and this is seen for antisera obtained from different species of animals (rabbit, monkey and goat). Thus the reason for this cross reaction should be advanced on the basis of structure, and as such the most likely possibility is the common structure of $\alpha$-subunit between the two hormones, the $\beta$ subunits being noncrossreacting (Sairam, 1983). Binding data using Scatchard analysis indicate that the crossreactivity is infact, while looking quite insignificant looks much more alarming when actual quantiation of the antibody capacity is done. We see that nearly $10-40 \%$ of the total capacity is directed against epitopes present in the antigen analogue, though on simple binding data it looks only about $<4 \%$. The other point to be considered is that in most of the cases the affinity constant for the antigen is 2-20 times more than for the antigen analogue. On this basis one can conclude that there are common epitopic regions between the antigen and the analogue (in this case oLH and oFSH). The decrease in the $K_{a}$ for antigen analogue indicates that though the epitopes are common, they may not be identically disposed sterically or otherwise. It is observed that all the antisera tested so far have given a single $K_{a}$ for the antigen, but occassional multiple affinity constants for the antigen analogue (figure 4, table 3) are seen, clearly establishing a steric block or a conformational change at the epitopic sites in the antigen analogue with respect to the antigen. Thus, combination of $\alpha$-subunit with different $\beta$-subunits results in a conformational change of the exposed $\alpha$-subunit portion between the antigen and antigen analogue. This change could be either a steric blocking of the epitopic site or a subtle conformational change at the epitopic site itself. Thus, even though the primary structure of the $\alpha$-subunit is the same around the epitopes, the 3 dimensional structure of these sequences is differentially altered by the combination with different $\beta$-subunits. The data of Hojo and Ryan (1985) from monoclonal antibodies to human FSH (hFSH) also indicate that an antibody to an epitope located at the $\alpha$ subunit binds poorer to the free $\alpha$-subunit than that in the native hFSH. Likewise it is seen in our laboratory that monoclonal antibodies to hCG bind to native hormone better than individual subunits (Rajan Dighe, unpublished results).

The other question raised because of the crossreacting nature of the antibody elicited to pure hormone is whether the antisera to oFSH can neutralise oLH. The data available in the literature (Rao and Moudgal, 1970; Moudgal et al., 1985) indicate that an antisera raised to one hormone is quite specific to that hormone as measured by its bioactivity or bioneutralising activity, under the conditions tested. The reason for this good specificity in bioactivity could be that either the hormoneantibody complex formed through the common epitope is biologically noninhibitory, or because of lower affinity for the antigen analogue, the analogueantibody complex formation between the antigen analogue and antibody is insignificant. As of now there is no positive experimental proof to decide the issue and further experiments are in progress towards this end.

\section{References}

Adiga, P. R. and Rama Murthy, C. V. (1983) Molecular biology of egg maturation (eds R. Porter and J. Wheten) (London: Pittman books) vol. 98, p. 111. 
Chandana Das, Gupta, S. K. and Talwar, G. P. (1985) J. Steroid Biochem., 23, 803.

Hojo, H. and Ryan, R. J. (1985) Endocrinology, 117, 2428.

Moudgal, N. R., Murthy, G. S., Rao, A. J., Ravindranath, N., Prasad, M. R. N., Kotagi. S. G. and Flora, M. (1985) Immunological approaches to contraception and promotion of fertility (ed. G. P. Talwar) (in press).

Mukku, V., Anand Kumar, T. C., Kumar, K., Rao, A. J. and Moudgal, N. R. (1974) Gonadotropins and Gonadal Functions (ed. N. R. Moudgal) (New York: Academic Press) p. 281.

Murthy, G. S. and Friesen, H. G. (1985a) J. Biosci., 7, 123.

Murthy, G. S. and Friesen, H. G. (1985b) J. Biosci., 7, 135.

Murthy, G. S. and Moudgal, N. R. (1986) J. Biosci., 10, 351.

Nash, H., Talwar, G. P., Segal, S. J., Lukainian, J., Johannson, E., Vasquez, J., Coutinho, E. and Sundaram. K. (1980) Fertil. Steril., 34, 328.

Raj, H. G. M., McDonald, G. J. and Greep, R. O. (1974) Gonadotropins and Gonadal Functions (ed. N. R. Moudgal) (New York: Academic Press) p. 271.

Rao, A. J. and Moudgal, N. R. (1970) Arch. Biochem. Biophys., 138, 189.

Rao, A. J., Kotagi, G. S. and Moudgal, N. R. (1984) J. Repord. Fertil., 70, 449.

Sairam, M. R. (1979) Arch. Biochem. Biophys., 194, 63.

Sairam, M. R. (1983) Hormonal proteins and peptides (ed. C. H. Li) (New York: Academic Press) vol. 11, p. 1.

Sheela Rani. C. S. and Moudgal. N. R. (1983) Hormonal proteins and peptides (ed. C. H. Li) (New York: Academic Press) vol. 11, p. 135.

Stevens, V. C. (1973) Obstet. Gynocol., 42, 496.

Sundaram, K., Chang, C. G., Laurance, K. A., Brinson, A. D., Atkinson, L. E. and Segal, S. J. (1976) Contraception, 14,639.

Talwar, G. P., Sharma, N. C, Dube, S. K., Salahuddin, M., Das, C, Ramakrishnan, S., Kumar, S. and Hingorani, V. (1976) PNAS (USA), 73, 218.

Wickings, E. J., Sreenath, B. R. and Nieschlag, E. (1982) Progress towards male contraception (eds S. L. Jeffecoate and M. Sandler) (New York: John Wiley and Sons) p. 71. 